\title{
Coreografia para dias de enxaqueca
}

\section{Lorena Galery Batista'}

Resumo: A série de fotografias são autorretratos realizados durante uma crise de enxaqueca e pretende funcionar como um ritual de cura. Transformar as impossibilidades que a enxaqueca gera no corpo, através do processo artístico, em uma linguagem. Um novo modo de expressão do corpo, suas dores e formas de sobrevivência.

Palavras-chave: fotografia. autorretrato. enxaqueca. corpo.

\section{Choreography for days of migraine}

Abstract: This series of photographs are self-portraits taken during a migraine crisis and are intended to work as a healing ritual. Transforming the impossibilities that migraine generates in the body, through the artistic process, in a language. A new way of expressing the body, its pain and ways of survival.

Keywords: photography. self-portrait. migraine. body.

I Possui graduação em Artes Visuais com especialização em Artes Gráficas e Fotografia pela Escola de Belas Artes da UFMG e atualmente é mestranda em Artes Visuais na linha de Processos Artísticos Contemporâneos em PPGAVUDESC. Vínculo institucional: aluna na Universidade do Estado de Santa Catarina, Av. Me. Benvenuta, 1907, Itacorubi. Florianópolis - SC, 88035-901. E-mail: logalery@gmail.com. ORCID http://orcid.org/0000-0001-9692-4539. Lattes iD: http://lattes.cnpq.br/2178843306049663. Florianópolis, Brasil. 


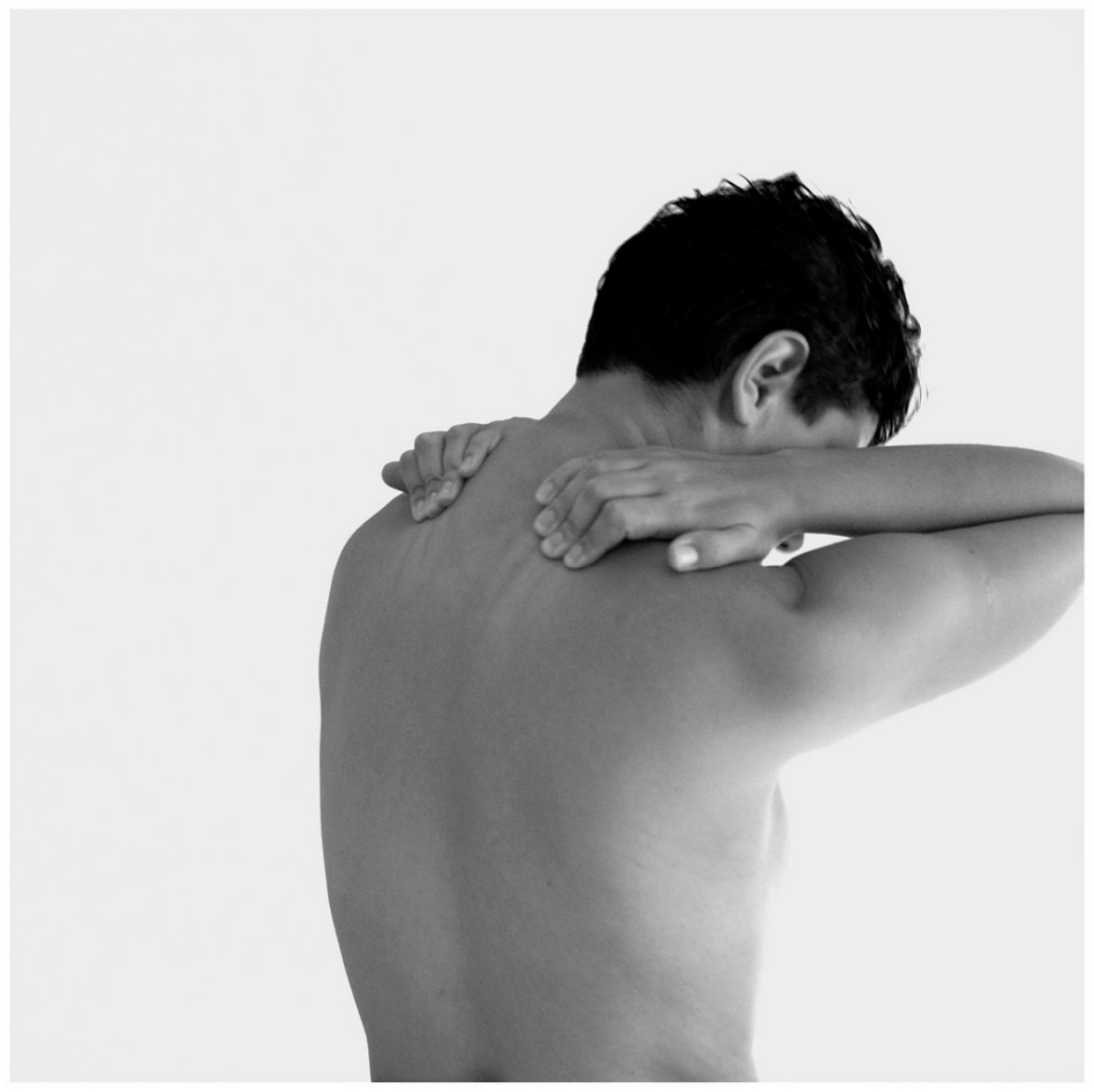

perceba que todos os analgésicos que você já tomou na vida tentam

escapar pelo músculo fraco dos seus ombros. não os deixe ir embora. 


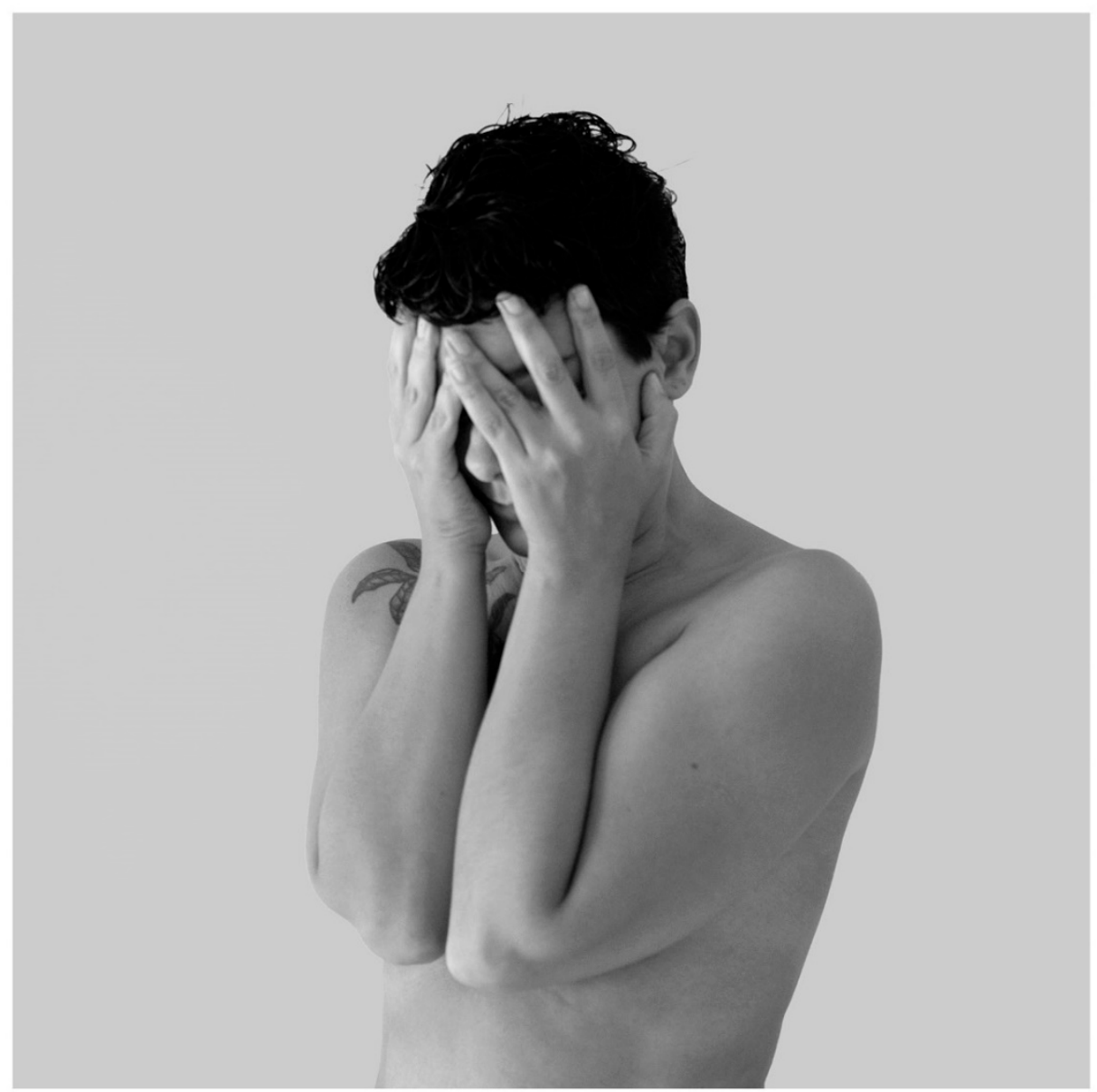

proteja os olhos com delicadeza e desespero.

hoje eles não servem para nada. amanhã, quem sabe. 


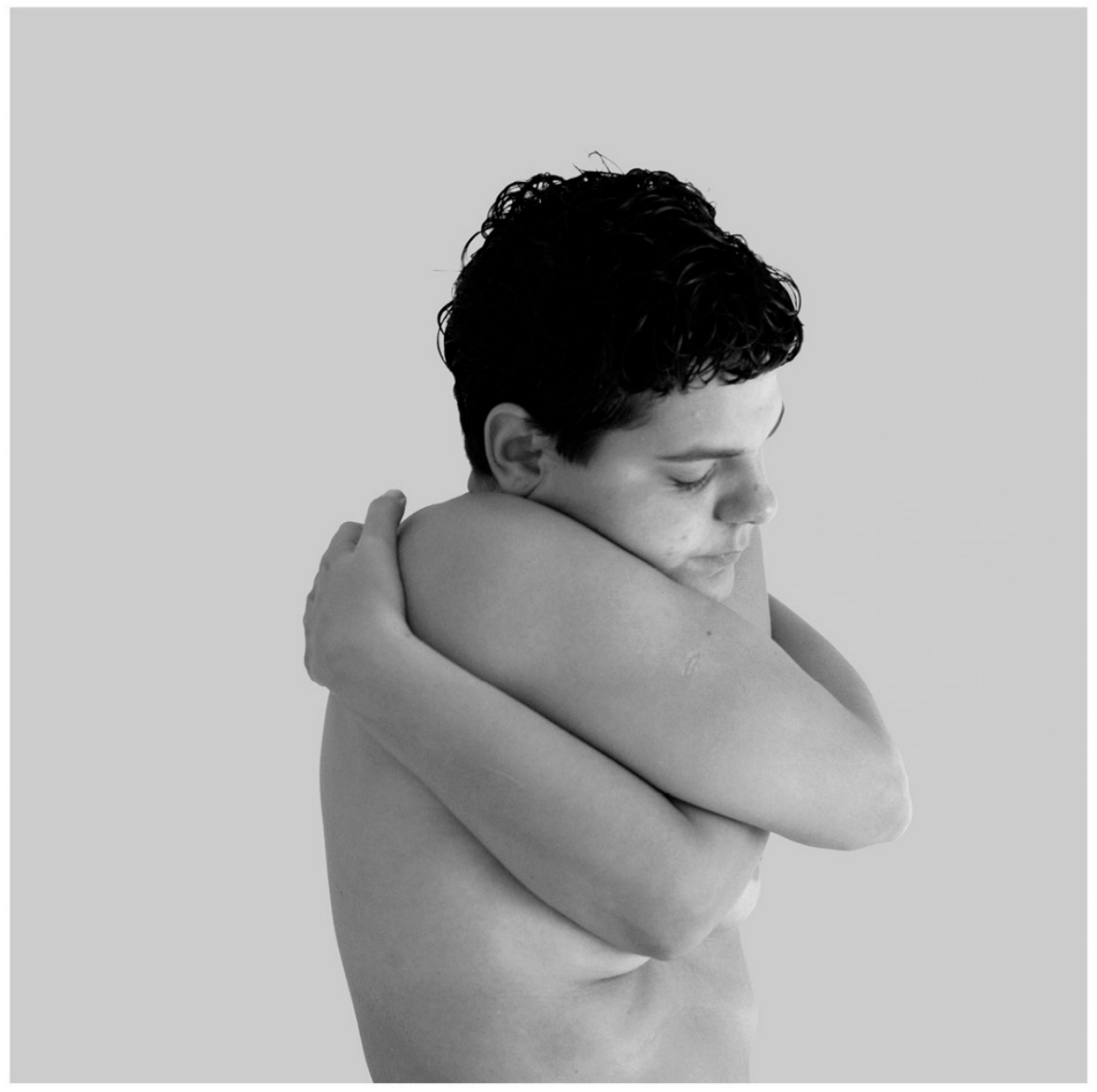

engula seus pensamentos como se fossem catarro.

quando chegarem ao estômago saberá se são indigestos. 


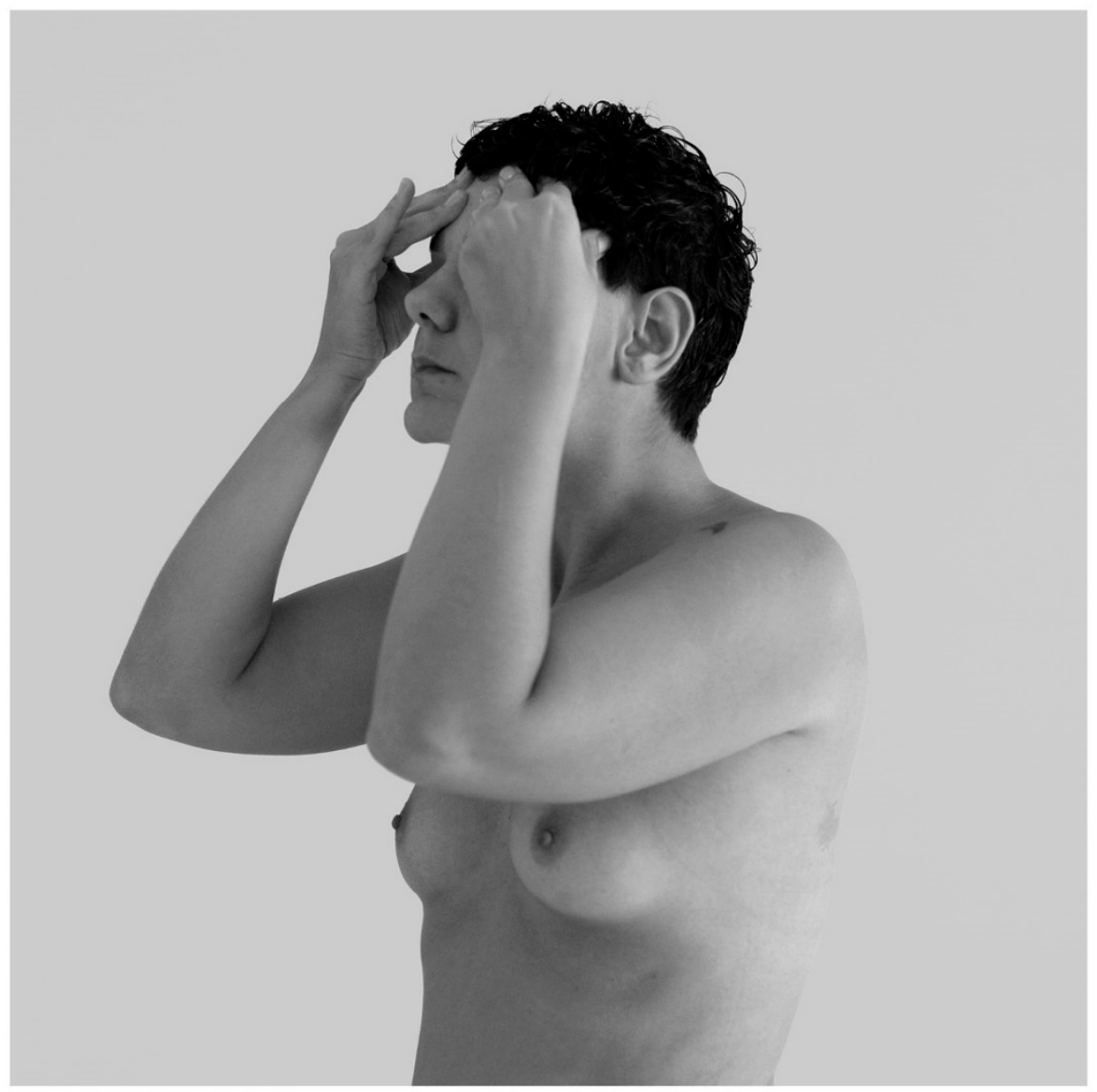

encoste o nariz no umbigo.

torça para que a enxaqueca vire dor de barriga. 


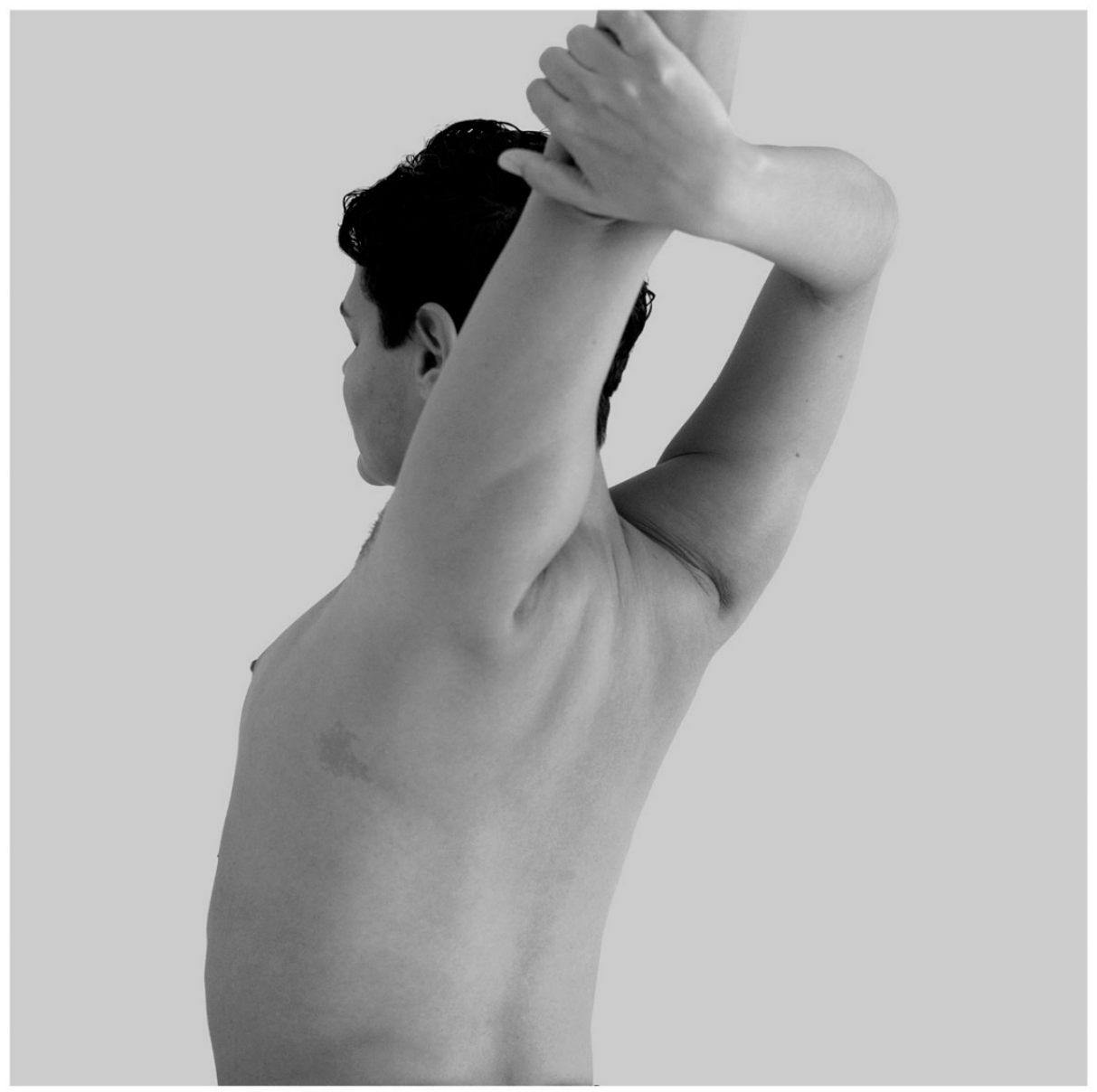

alongue as costas de forma que cada vértebrase quebre.

junte os caquinhos e coma o que tiver dentro. 
Figuras 1 a 5

Coreografia para dias de enxaqueca, 2020

Fotografia digital

5 imagens $30 \times 40 \mathrm{~cm}$ cada

Recebido em 06 de junho de 2020 e aceito em 03 de março de 2021.

Este é um artigo publicado em acesso aberto sob uma licença Creative Commons

(cc) $\mathrm{BY}$ 